\title{
Transformative roles of people and places: learning, experiencing, and regenerative action through social innovation
}

\author{
Abid Mehmood ${ }^{1}\left(\mathbb{0} \cdot\right.$ Terry Marsden $^{2} \cdot$ Alice Taherzadeh $^{2}\left(\mathbb{0} \cdot\right.$ Lorena F. Axinte $^{2}\left(\mathbb{0} \cdot\right.$ Cátia Rebelo $^{2}(\mathbb{0}$
}

Received: 11 March 2019 / Accepted: 9 October 2019 / Published online: 16 November 2019

(c) The Author(s) 2019

\begin{abstract}
This paper discusses the transformative role of people and the places which they inhabit. It advocates the richness and multiplicity of actors and understandings to drive sustainable place-shaping practices. Grounded in the interdisciplinary placebased conceptualisation of social innovation, the paper aims to progress a holistic conceptual framework which integrates the active processes of learning, experiencing, and regeneration to tackle the complex challenges of sustainability. The discussion argues for moving beyond the conceptual deliberations into practice-based research. The framework proposed brings together three different lenses: first, transformative learning as an approach to experiential pedagogy with focus on education and learning based in local communities and the surrounding places; second, experiencing place through sense-making to help people relate closely to their values and meanings of place; third, regenerative action to reverse and recuperate from the negative impact of humans on the environment and promote place stewardship. Through a dynamic combination of these processes, new socially innovative agency is created. Empirical examples of this agency have been captured in this paper from a series of projects which were part of the SUSPLACE programme. In conclusion, we associate the interactive nature of this agency with sustainable re-learning, re-experiencing, and re-generation processes to reshape places in a transformative way.
\end{abstract}

Keywords Social innovation $\cdot$ Regenerative development $\cdot$ Transformative learning $\cdot$ Visual narratives $\cdot$ Sustainable placeshaping

\section{Introduction}

The debates and applications of transformation as a notion representing departure from unsustainable practices and policies has been substantially advanced in the recent sustainability science scholarship. From knowledge integration to user engagement, co-deliberation and co-creation transformative sustainability research has strived to bridge the path from knowledge to action, research to policy, and policy to practice. This has helped with addressing the translational

Handled by Erik Mathijs, Katholieke Universiteit Leuven, Belgium.

Abid Mehmood

mehmooda1@cardiff.ac.uk

1 School of Social Sciences, Sustainable Places Research Institute, Cardiff University, Cardiff, UK

2 School of Geography and Planning, Sustainable Places Research Institute, Cardiff University, Cardiff, UK issues between radical thinking and imagining and materialising equitable common futures (Lang et al. 2012; Wittmayer and Schäpke 2014; Temper et al. 2018). Arguments in this respect have referred to the need for "reconnecting people to nature" as among key 'sustainability interventions' (Abson et al. 2017: p. 30).

Acknowledging the normative dimensions of sustainability transformations, discussions also refer to social value considerations for implicit negotiating, eliciting, and transformative change to improve human conduct towards nature (HorceaMilcu et al. 2019). Critical scholars, however, warn that the notion is at the verge of losing its radical character due to its often-casual translations into the mainstream practice and policy (Pelling 2014). Blythe et al. (2018) in this respect has argued that uncontextualized translation from theory to policy may result in ambiguous practice-possibly changing a descriptive notion into a prescriptive one-when applied as a change mechanism. Papers in this Special Feature have acknowledged these concerns in favour of a place-based conceptualisation of transformation thinking, particularly to address the translational 
problems in research, policy, and action. In this paper, we address how place-based forms of social innovation can create conditions for sustainable transformations.

A place-based conceptualisation allows looking at the role of communities in accordance with the locale and sense-making (Relph 1976; Cresswell 2014) as well as social interactions (Massey 1994). At the same time, it acts as a bridging notion both in the bounded and relational senses to reinforce the integrating and interactive aspects of human-nature relationships (Marsden 2013). As argued by Horlings et al. (this issue), much of the recent place-based transformations literature tends to emphasize the role of people in making, shaping, and keeping places. There is however room for deeper contemporary investigations on the role that places play in shaping attitudes, behaviours, norms, cultures, societies, etc. This gap in academic literature could be attributed to the contemporary scholars' fear of being pigeonholed into the legacy of environmental determinism that asserted the primacy of ecological and environmental causes upon social, cultural, economic, or political attitudes and practices (Peet 1985). To tackle this conundrum, places, within the scope of this paper, are seen as sites of incubation and spatial networking that also inspire social initiatives and innovations.

Human agency within this consideration can be seen as an initiator of sustainable place-shaping by shifting boundaries, combating social exclusion, establishing links between different spatial scales and communities (upscaling), and building new linkages. Innovative socio-spatial practices can, therefore, provide an interface between places and people where self-efficacy, local values, and deviance from unsustainable practices can lead to sustainable place-shaping. A conceptually informed application of place-based sustainability transformation can help to establish what motivates the transformation (needs), what is to be transformed (challenges), how to transform (innovations), and which practices will help achieve the transformation. A place-based view here helps to accommodate reflexive dialogues and negotiations that can reveal valuable local knowledge and co-define how local actors relate themselves with places' experience and make sense out of it (Horlings 2018).

In this respect, our empirical research and analysis addresses the following questions: what are the path-breaking avenues for creating transformative places and communities? Who are the main change agents for shaping and mobilizing sustainable places? And, how do collective placebased knowledges contribute to the places of (social) innovation and vice versa? To identify the opportunities reflected in these questions, we refer to a transformative approach to place-based social innovation in the form of a trilateral empirical framework to highlight the importance of learning in collaboration with the communities, experiencing the communal senses and meanings of place, and promoting regenerative practice to foster a rejuvenated human-nature relationship. The place-based research lens also strengthens different disciplinary views to understand the transformative role of sustainable place-shaping practices. Empirical cases are discussed based on selected projects conducted under the auspices of SUSPLACE-Sustainable Place-Shaping (https ://cordis.europa.eu/project/rcn/198260/factsheet/en), a programme of research training and development conducted in 2015-2019 (see Acknowledgements). The programme brought together 17 early career researchers from 6 Europeans universities and nurtured their skills through training, development, placements, and secondments at various academic and non-academic institutions across Europe.

In the following, Sect. "Social innovation: a sustainable place based view" highlights and offers justification for a place-based view of social innovation using people-place dialectics and the role that deviance and disruptiveness play in socially innovative practices. Section "Towards transformative place-shaping through learning, experiencing, and regenerating" presents and reflects upon concepts and modes in transformative place-shaping, introducing a proposed trilateral approach that encompasses transformative learning, experiencing place, and regenerative action with the help of selected SUSPLACE case studies as empirical examples. Section "Discussion: a trilateral approach to transformative place-shaping" synthesizes and discusses this trilateral approach emphasising the intricate relationships between regeneration, learning, and experiencing. Section "Conclusion" concludes by discussing the transformative and socially innovative elements for place-shaping, and identifies further avenues to be explored for research, policy, and practice.

\section{Social innovation: a sustainable place based view}

Social innovation is a spatially aware and scalarly embedded approach that aims to alter the status quo, seek opportunities for deviance, and induce change. In its place-based embodiment, social innovation is both "a practice (collective satisfaction of human needs) and a process (changes in social relations, empowering governance dynamics)" (Moulaert and Mehmood 2019: p.2) with a particular focus on combating social exclusion and driving societal change (Moulaert et al. 2013). Social innovation, in its policy and practice conceptualizations, helps to disseminate spatially embedded and place-specific initiatives. It can, therefore, assist in redefining the interdependence between places and people both in terms of the bounded and the relational framing of place. With this conceptual focus, social innovation which we can argue has a transformational potential that can not only help to explain how changes occur at place-based level, but also inform how communities adapt and respond to such changes, especially in the situations of crises (Baker and Mehmood 2015). 
A place-based approach builds on the specific resources, assets, capacities, and distinctiveness of places (Horlings 2018). Socially innovative actions are both people- and place-oriented, since the principal purpose remains the needs satisfaction and empowerment of communities to address societal challenges (such as reducing socio-economic disparities, adapting to and mitigating the effects of climate change, etc.) through collective action. Sociospatial relations are also intrinsic to the places in which collective actions take place. Hence, the prospects of places to play a role in social innovation remain contingent with the transformative potential of social relations (Moulaert and Mehmood 2011). It needs to be recognized that whilst there are social innovators transforming places, there are also places of innovation transforming people.

This paper illustrates the multiple interplay between people and places in transforming social relations and practices. To this purpose, the processes of learning, experiencing, and regeneration are referred to for their importance in transformative change. It is worth clarifying here that not all changes are necessarily transformative, and that to stimulate innovation, places do not have to be manifestly fertile or brimming with opportunities. Arguably, economic, political, social, and environmental constraints can also become drivers of socially innovative actions and initiatives. In fact, such actions often stem from those places of constraints (or crises), where vulnerable actors have limited opportunities to access and use local resources. Their need to reconnect with the contiguous nature is thus, even more stringent. Innovations in such conditions could be both disruptive and life changing in either sense. Innovative actions, however, may also be under pressure to either become models of bottomup creativity to improve socio-economic and environmental conditions, end up as failures due to lack of resources, capacity, local support, etc. (Stott and Tracey 2018), or find a way in-between.

Successful transformation of places through social innovation still does not guarantee durability of initiatives unless there is willingness and possibility to upscale or sustain the collective initiatives (Mehmood 2016a). Situations of crisis and vulnerability, therefore, can also become sources of transformative change to empower communities and lead to the formulation of new trajectories of radical innovations, foster new pathways for social change, and provide solutions to complex socio-ecological challenges (Mehmood, 2016b). Transformative social innovation in this respect has been offered to reinforce social innovation as a theory of social change (Avelino et al. 2017). However, the literature so far has remained more sector- or case-specific, with a focus on the revolutionary or game-changing aspects of transformative change rather than the evolutionary and strategic features of socially innovative and place-based actions and initiatives.
In terms of the people-place dialectic, a transformative social innovation perspective can de-romanticize any assumptions about the relationships between people and places. These relationships are often bilateral and can be affected by mutual experiences, how these experiences may associate or dissociate people from specific places. But also, these experiences may motivate people to develop new and stronger relationships with the respective places. The multiplicity of the conflicting experiences is what can help define place as a representation larger than a mere geographic area or bordered entity, more as a variable or interconnected network of identities that are only constrained by the capacity of the institutions (practices, habits, routines) that shape, make, or keep those places. The role of local actors and stakeholders in socially innovative initiatives is what defines and supports social cohesion and local citizenship for inclusive social innovations. This creates new spaces for interaction and everyday practices to reinforce community life through bottom-linked actions as interfaces between topdown policies and bottom-up initiatives (García et al. 2015). Similarly, social policies or movements to ward off crises and conflicts by the concerned citizens or activists can also take place by means of the deviant behaviours to disrupt the precarious conditions and formulate new social change initiatives and strategies.

Deviant or disruptive behaviours do not necessarily have to be repulsive or negative in nature for the planners and policy makers. In fact, several local authorities around the world have positively responded by adopting their governance mechanisms in accordance with the demands of the 'deviant citizens' to change the status quo through social innovation (Arthur 2013). A good example is the formalization of temporary use of vacant spaces. In Barcelona, for instance, as a bottom-linked practice, people were allowed to collectively appropriate places and spaces designated by the municipality (Axinte 2017). Citizens revived these places and made them more accessible to the wider community, providing services that were previously scarce. Such strategies have been subsequently adopted by many formal (public and private) landlords to reinvigorate and revitalize derelict spaces. This, however, does not rule out the possibility of specific agendas of the social actors. Transformations in social relations and consolidation of dispersed agendas and initiatives can best occur through collective action that transcends local spheres to overcome the 'localism trap' through spatially articulated places of interactions in a relational sense (Born and Purcell 2006).

There is, therefore, a need to elaborate the contexts and applicability of transformative processes in the conceptualization of social innovation for sustainable place-shaping. In the following, we discuss an empirical approach based on interrelated aspects of place-based learning, experiencing, and regenerative actions. 


\section{Towards transformative place-shaping through learning, experiencing, and regenerating}

The proposed approach considers people-place relationships as transformative, building on the ideas of developing such interactions that can help with translating people's experiences of places, and produce collaborative dynamics to regenerate human and natural systems in a holistic manner. Learning, in place-based pedagogy, refers to experiential acquisition of knowledge, transformation of perspectives, and building of skills through interaction with local places and place-based knowledges. The landscapes of learning encompass diverse sets of people-place relations and can cover a broad range of activities, developing learning through observations, social interactions, and dialogue, and thus contributing to the transformative processes that bring people and places in closer proximity (Bäckman et al. 2019). Experiencing can be related to the processes of apprehension and sharing the sense and identity of a place. Shared transformative experiences can help to understand how place relationships are discerned and visualised, stimulate inclusive forms of identity building, and acknowledging the transformative agency of people to shape the respective places by means of values, ideas, and needs (Rebelo et al. 2019). Regeneration in its place-based articulation facilitates contextualizing and identifying the distinctive character of society and place (Axinte et al. 2019). The regeneration hypothesis helps to effectuate a worldview through which human and natural systems can form mutually beneficial symbiotic relationships (Cole 2012). It requires communities to go beyond sustaining and make concerted efforts to positively contribute to and enrich the environments which they inhabit. Thus, a regenerative view transforms the relationship of people with place, from exploiters to partners who co-evolve (Mang and Haggard 2016).

When considered in a trilateral nexus, the approach allows sharing the sense and perception of place in shaping social practices, norms, cultures, and other mutual sociospatial understandings. This interactive combination of the overlapping yet transformative processes is represented in Fig. 1 to help redefine, reimagine, and reinterpret the conceptualization in sustainably making, shaping, or keeping the people-place relationships. The following discussion further elaborates the nexus approach, highlighting interrelationships between transformative learning, experiences and senses of place, and regenerative collective action. The trilateral elaboration also addresses the empirical questions posed above to characterize the path-breaking avenues for transformative places/communities, locate the change agents for sustainable place-shaping, and build collective placebased knowledges to establish the places and spaces of (social) innovation.

\section{Transformative learning}

Developing pathways to sustainability relies on adults first unpicking the myths of our current system and then developing new frames of reference to account for the ecological, social, and economic disasters we see unfolding before us. Such radical shifts in mindset or consciousness-crucial for sustainability transformations to occur-are the result of what is termed transformative learning (TL) (Mezirow and Associates 2000; Burns 2015). Through case studies from
Fig. 1 A nexus approach to learning, experiencing and regeneration

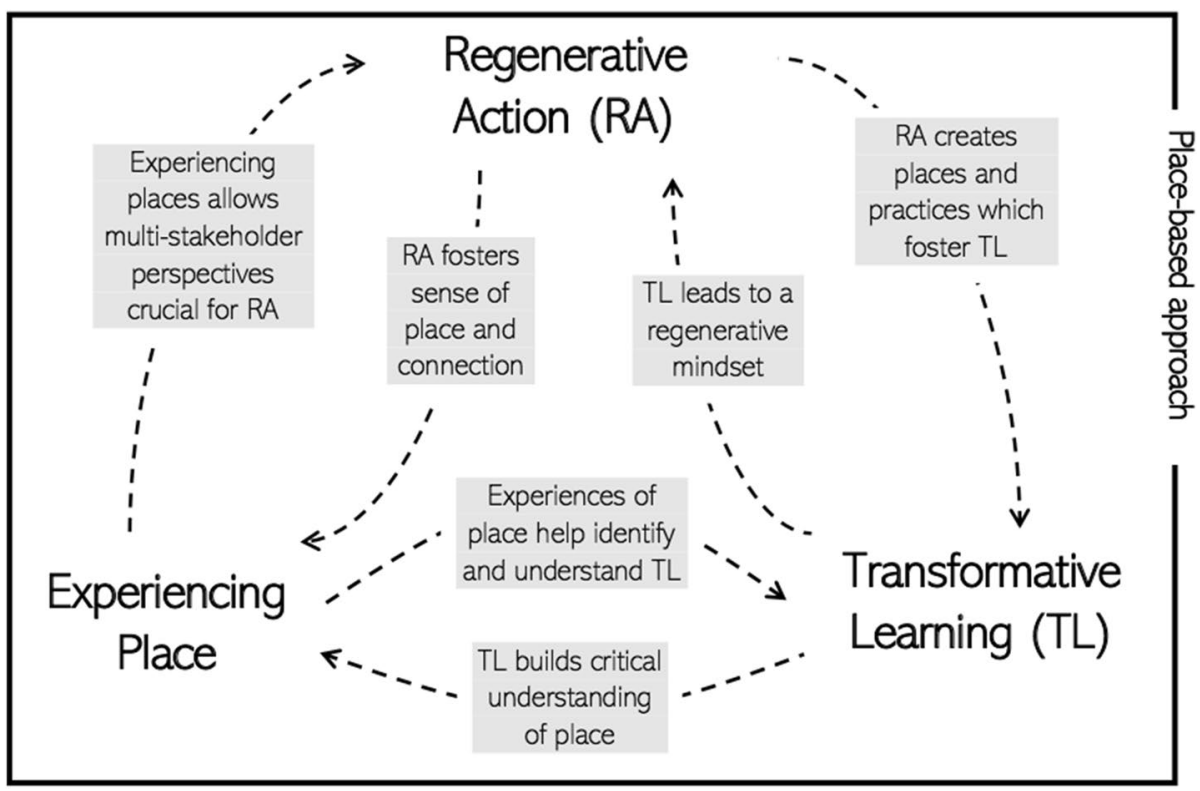


the SUSPLACE programme, we examine how TL theory could contribute to sustainable place-shaping research and actions, highlighting the importance of regenerative practices and place-based experiences in fostering such learning.

Transformative learning theory has been key to understanding adult learning since first introduced by Mezirow some 40 years ago (1978). It is the process of perspective transformation from 'frames of reference' that are habituated and assimilated through childhood, to ones that are more fully developed by being: inclusive, differentiating, permeable, critically reflective, and integrative of experience (Mezirow 1996). More recently, it has received significant attention across multiple disciplines, particularly those focused on sustainability, as well as in different bodies of educational research (Taylor 2017). For more extensive discussions on the theory's evolution, see the various valuable reviews at different points of its development (Calleja 2014; Kitchenham 2008; Taylor 2007; Taylor and Cranton 2013).

In the last decade, TL has found its way into Higher Education literature with a particular focus on perspective transformation towards developing sustainability competencies (Burns 2015; Leal Filho et al. 2018; Leicht et al. 2018; Wals 2010). This has led to additional, sometimes critical, contributions to the theory including the need for a restorative learning perspective (Lange 2004) and the move beyond TL to 'Transgressive' (Lotz-Sisitka et al. 2015) or 'Transcendental' Learning (Peters and Wals 2016). Here, we focus specifically on a place-based approach to transformative learning and, through case studies from the SUSPLACE programme, identify the contribution TL can make to sustainable place-shaping. For sustainable place-shaping initiatives, uncovering transformative learning experiences is relevant at three stages: exploring learning that has motivated action, planning to actively integrate learning into practices, and the perspective transformations that occur through participation.

- The 'Connected Learning Spaces' project in SUSPLACE explored the role of experiential learning in Higher Education for Sustainable Development (HESD). Alice Taherzadeh investigated the transformative potential of Service-Learning, an experiential place-based pedagogy. Service-learning combines community service and academic learning focusing on critical reflection, citizenship, and mutual benefits for students and communities. The Tyfu i Ddysgu (Growing to Learn) project (https:// blogs.cardiff.ac.uk/growing-to-learn/) in Cardiff, Wales, connected university students with local community gardeners to co-design practical sustainability projects. Taherzadeh found that the potential of such projects for fostering transformative sustainability learning was deeply linked to the extent to which students formed connections with the community gardeners and gardens themselves, i.e., their sense of place. Whilst student men- tal health and disconnection with place were considered as barriers to engagement with regenerative practices, integrating place-based learning within the curriculum has the potential to address such issues. It can lead to regenerative practices both in terms of sustainability and mental health if students are supported in developing a sense of place and "reinhabiting" places, that is, "to pursue the kind of social action that improves the social and ecological life of places, near and far, now and in the future" (Gruenewald 2003: 7). Fostering transformative learning through formal education can serve to strengthen existing place-shaping actions through creating new knowledge networks (Horlings 2016) which enable mutual learning and sharing of knowledge and resources by grounding education in local place-shaping initiatives, as was seen in Tyfu i Ddysgu.

- Empirical work in Finland has further highlighted the role of Green Care practices as sites of empowerment and transformative learning, developing the emotional awareness and relational responsibility (Moriggi et al. 2019). Through an ethics of care approach, Moriggi et al. view ethically-informed practices as spaces of experimentation and incremental change through joint learning to drive sustainability transformations. With a careful development and adaptation of actions and perspectives, the authors emphasize the importance of the slow and responsive transformative learning which comes through caring for and intimately knowing a place.

- Referring to transformative potential of social innovation, Siri Pisters' work on ecovillages and sustainable living has looked at a specific cultural-spiritual conceptualization of place-based transformative learning to understand knowledge transfer in relation to sustainable place-shaping initiatives (Pisters et al. this issue). Based on the literature and her work on ecovillages in Finland and Portugal, Pisters developed a place-based learning framework for 'ecological consciousness' centered on connection, compassion, and creativity. This framework was used to identify the processes of transformative learning that have led to, and are a result of, participation in ecovillages. Understanding these processes is key to identifying both how sustainability initiatives can be scaled out, as well as how they function as important sites of deviant social innovation (Arthur 2013) by creating people-place relationships which challenge dominant ways of being and can, therefore, promote paradigmatic shifts in thinking.

- A further case related to transformative learning is that of the Latvian Permaculture Network. Coordinated by Felcis (2019), the network emphasizes continuous processes of knowledge-building and sharing in the wider permaculture movement and the weaving of place-based traditional knowledge with novel approaches between local 
and global levels of civil society actors. Here, learning remains a key aspect of regenerative practices with the theoretical framework of permaculture promoting conscious interplay between traditional place-based and new knowledge and encouraging a reflection on the origins and broader political and social contexts of land-based practices.

Due to its relevance to sustainability, transformative learning theory is now developing through interaction with multiple interdisciplinary lenses. This can be seen in Moriggi's et al. (2019) integration with an ethics of care, Pister's et al. (this issue) application of cultural-spiritual influences and Felcis's (2019) consideration of learning within sustainable agriculture. Both Moriggi and Taherzadeh's work highlight the importance of developing sense of place in fostering transformative learning towards regenerative practice. Pisters has explored the potential for understanding and scaling out sustainable place-shaping practices through drawing out the transformative learning experiences which motivated action. Felcis identified the need for critical reflection on existing frames of reference to move away from unsustainable practices and collectively integrate traditional and novel knowledge for new regenerative practices. Transformative learning contributes to socially innovative practices by allowing critical reflection of community needs, socio-political empowerment through collective perspective change, and improving social relations through sustainable place-shaping. The next section explores further the sense of place and place-based knowledge, referring to practical methods which can contribute to community-based transformative learning research and practice.

\section{Experiencing place}

Experiencing place refers to sense-making, which occurs over time through the relational interactions between people, their settings, and their social world (Horlings 2018). Looking at place as an outcome of multiple, dynamic, and constantly changing social interactions (Massey 1994), the process of experiencing place is equally complex, dynamic, and subjective. Unsurprisingly, in this process, place is perceived and experienced differently as various attributes, values, senses, and identities are attached to place (Horlings 2015). Identifying and understanding the plurality of values and characteristics of different actors can also uncover new place-based knowledges and contextualization. It recognizes the central role of place and belonging, which is subjectively affected by peoples' own narratives, perceptions, and attachments (Vanclay 2008).

In this respect, the notion of sense of place is key to explore the process of place experiencing. Sense of place refers to knowledge, meanings, and emotions developed either individually and/or collectively through individuals' everyday life experiences (Tuan 1980). It is closely connected to local actors as well as to personal memory and self, including different senses-sight, hearing, smell, movement, touch, and imagination (Relph 1976), which inform people's encounters, behaviours, and actions towards their place. Therefore, making sense of it requires more than simple expression about a place. It requires innovative placebased approaches, to facilitate visual narratives which can provide diverse, multi-layered, and sensorial (Pink 2011) narratives of place and place practices ('place-based' knowledge), as well as reveal varied values and meanings attached to it. In research, participatory visual methods help to elicit memories, emotions, and tacit cultural knowledge (McDougall 2011). Narratives or story telling as a methodological framework can empower individuals, communities, and networks, and serve as an alternative that respects the complexity, social fabric, geography, and socio-political contexts of people and places (Lucarelli and Giovanardi 2014). It can, therefore, be argued that participatory visual methods can serve as a powerful approach not only to understand peoples' sense of place and multisensorial experiences of places, but also to engage them into meaningful reflections (re)negotiations and possible regenerative actions and, indeed, practices of social innovation. More specifically, experiencing place is the basis for place-based sustainable, grounded and collective cherished and supported initiatives, which may lead to social innovation. This, in turn, may also reshape how people relate and perceive their place resulting in an iterative and interconnected process.

The concept of experiencing place has been applied and explored by two distinct SUSPLACE projects as below which, despite their distinctive nature, converse on a set of methods-particularly visual methods-to explore how local actors and communities experience and share their sense(s) of place.

- Cátia Rebelo's work in Portugal and Wales explored how co-produced visual narratives help local actors to define and articulate their sense(s) of place and placebased knowledge, and how this may help to transform people and places (Rebelo et al. 2019). For this purpose, an interconnected, non-linear four-stage conceptual framework was devised to guide the data collection in two comparative case studies. More specifically, 'visual documentaries making' as a collaborative tool with a participatory action research element was applied. The participatory component helped to include, energize, and actively empower people to define, for themselves, the rich ways in which their place and place meanings can be articulated. The process of co-defining and co-creating the documentary, which embodied a more inclusive and 
place-based representation of place, transformed the participants' relationship with place. It helped them to identify new meanings and unveiled (re)connections with the place as well as with the other participants. Connections were nourished and shared via similar sociocultural experiences of place such as ideas, values, and actions to preserve local heritage. One of the main conveyors in the process was a local folklore group, established to preserve traditional songs of the place and its social connectedness (e.g., agriculture, social events). This was discussed through visual narratives such as excerpts of a folk song. The experience resulted in high levels of socio-political engagement, as well as feelings of empowerment and local capacity. It became a catalyst, reinforcing people's collective agency and environmental stewardship to promote and preserve the meanings, values, and identity of place. Dialogues were transformed into action when participants took initiative to organize a public presentation showcasing the documentary. People subsequently joined efforts to shape and steer the future of their place by articulating the visual narrative of the social nature of their place to a wider audience: friends, family, visitors, and local authorities.

- Another case study work explored ways to engage communities in discussions about their desirable futures through the use of arts-based, visual methods. The Sense of place project was conducted by Grenni in the Finnish town of Mänttä. It was developed alongside the needs expressed by the town's planning department, culminating in a series of workshops to explore local cultural narratives rooted in the sense of place (Grenni et al. 2019). The workshops were structured around a co-creation exercise informed by previous work on arts-based methods for transformative engagement developed within SUSPLACE (Pearson et al. 2018). Participants were initially given prompts to express current representation of their town on a map along with the meanings and values they attach to the place. Following it, they were prompted to co-create storylines of desirable futures for their town and express them visually through a collage, to harness intuitive knowing and aesthetic sense-making (Butler-Kisber and Poldma 2010; Pearson et al. 2018). The resulting narratives represented aspirational ideas of possible futures, reflective of the participants' sense of place and openly acknowledging local needs and values. Some key themes represented included the importance of caring for nature, pride on the quality of local services, a general sense of community, and the unique artistic history of the place.

Sustainable place-shaping often stresses that sustainability can only be achieved if local actors and their 'place-based' knowledge are effectively engaged in discussions and processes of decision-making, as mentioned above. However, this is not an easy task as questions remain about effective and inclusive engagement that can lead to transformative actions. The experiencing of place approach brings empirical evidence on how engaging people to explore their sense(s) of place through collaborative visual methods may be an effective way to address this issue. Both projects illustrate how collaborative visual methods (mapping, collage, videos, etc.) can become a valuable tool for engaging local actors and illustrating their values, meanings, and senses of place, as well as critical 'place-based' knowledge about places' past, present, and possible futures. Furthermore, participatory visual methods were not only crucial to stimulate multiple senses in the process of sense-making but also a tool to include a diverse range of participants, particularly, illiterate or poorly educated people, who generally feel uncomfortable with written methods. The videos and images were also important for people to discuss in-depth and complex issues and a complement to their verbal expressions in their native languages avoiding loss of information in translations.

This corroborates Horlings' (2015) argument that the dialogues which stimulate people's senses of place are a valuable source of information for policymakers in the processes of participative deliberations. Using collaborative visual tools worked as an important leverage for transformative community action to disseminate the video documentary to wider audience. The documentary enabled citizens to convey richer and multisensory messages and experiences which could not have been expressed in texts (e.g., folk songs). It became a source of place-based knowledge that can be accessed by people around the globe through popular social media (Twitter, Facebook, YouTube, etc.).

These empirical cases also reveal significant interconnections between place experiencing, transformative learning, and regenerative action (Fig. 1). During the collective and reflexive processes of making sense of their place, participants learnt from each other and became more aware of place characteristics. They then shared this 'place-based' knowledge with others through visual narratives, allowing to capture, learn, and share individual and collective experiences. This knowledge is not only important to inform the processes of transformative learning, but also to exemplify how knowledge can be co-created through socially innovative, engaging, and multisensorial action. This is equally true in the quest for regenerative approaches beyond sustainability, since this complex understanding of place and localised knowledge and experience is crucial to radical actions and social innovations that can be shaped and carried on by local actors. 


\section{Regenerative action}

Drawing from ecology and originating in the design field (Lyle 1994), regenerative action entails a radical and disruptive mindset shift among citizens. The multiple, interconnected crises affecting our world are now demanding approaches which actively repair the environmental, social and economic damages, 'before we can think about sustaining' (Ichioka 2018). Efficiency and 'mere sustainability' are no longer enough, and humans must strive to regenerate the health of places and cultures (Girardet 2015; Mang and Haggard 2016; Wahl 2016), seeking to 'support the co-evolution of human and natural systems in a partnered relationship' (Cole 2012).

Regenerative approaches surpass the idea of doing less harm, with the aim of affecting positive change. Used in an interdisciplinary perspective, there is wide consensus that regenerative practices are borne from the uniqueness of a place (Mang and Reed 2017). Regenerative action, therefore, initiates transformation and highlights the need to constantly reevaluate and adapt to new conditions-an aspect particularly important in the face of rapidly changing climate conditions, for instance.

Requiring a deep understanding of people-place interrelations and context, regenerative approach advocates systems-thinking capacities in an adaptive manner. Through this holistic stance, parts cannot be treated in isolation. The approach, however, remains highly aspirational, making it difficult to operationalise. Besides, the deeply integrated nature (Mang and Reed 2017) of regenerative action, and the long-term framework in which it operates, may not necessarily align with political programmes, rapid economic returns, or even societal expectations. Recognising the strengths and weaknesses in conceptualisation of regenerative action, two different examples are mentioned below from the SUSPLACE research that studied its application documenting its potential in transforming places and communities.

- Based on the permaculture and bioregionalism roots of regenerative practice (du Plessis 2012; Girardet 2015; Mang and Reed 2017), Felcis (2019) has explored the capacity of the permaculture movement to shape regenerative practices and places beyond just farming. He connected permaculture to three types of regenerative transformations: organic growing or gardening, ecological building, and ecological lifestyle practices. In Latvia, these transformations are supported by the Latvian Permaculture Association (LPA), which has expanded its membership and range of activities in recent years. The LPA has applied several successful projects including four permaculture school gardens (outsourcing the methods), a seedbank and database with international seed exchanges, and regular workshops on ecological construction, sustainable heating, and renewable energy solutions. The Association's structure remains rather fragile due to its dependence on a small circle of skilled and highly motivated individuals. Despite growing popularity, the movement's impact also remains relatively limited. Notwithstanding these challenges, Felcis' work illustrates the progressive links of regenerative action with transformative learning and place experiencing. Permaculture supports such regenerative actions that can educate and empower people to become more self-sufficient and conscious of socially innovative actions and initiatives.

- The second empirical case associated regenerative development with top-down policy in Wales. The Wellbeing of Future Generations Act (WFGA) became one of the first (and few) pieces of legislation in the world to enshrine sustainability into national constitutive documents in 2015. A Future Generations Commissioner (FGC) guards over the interests of (yet) unborn stakeholders, ensuring that actions of the public sector bodies contribute to all of the seven national well-being goals referring to Prosperity, Resilience, Equality, Health, Community Cohesion, Culture and Global Responsibility of Wales (National Assembly for Wales 2015). The WFGA is an evidence of transformative policy and regenerative practice as it affects several domains of change (Fazey et al. 2018). The Act entails cognitive changes, shifting the ways in which Wales measures progress, from growth to well-being. It does so through structural changes, crystallised in the form of a policy shift which encourages Welsh public bodies to be proactive in helping communities become more sustainable. Besides, the WFGA requires relational changes and supports interactions and collaborations between a variety of stakeholders, since the well-being goals cut across traditional silos. Unfortunately, functional changes (e.g., practices that disrupt the status quo) are still limited. In a series of interviews with the political and executive leadership of Cardiff Capital Region, Lorena Axinte identified many leaders' resistance towards implementing the Act, largely seeing it as an administrative burden that prevents advancing the top-down and quick-fix solutions. FGC's influence, however, remains restricted, since she can only advise and challenge, but not halt unsustainable projects that may affect the well-being of people or places. The act is also criticised for offering flexibility for public service bodies to an extent that ambiguous concepts such as 'long-term' and 'reasonable steps to achieve well-being objectives' leave room for interpretation and may lead to the lack of radical ambitions and strategic action (Davies 2016). 
As evident from these cases, regenerative action requires a mindset shift through which transformative practice seeks not only to sustain, but to revitalise and enhance socioecological and socio-economical systems. In the Latvian case, changes were instigated bottom-up, by individuals and communities of interest looking for alternative lifestyles. In Wales, the framework was created in a progressive but topdown way of thinking at the governmental level. None of these can be expected to succeed without a critical mass of bottom-linked support. At the same time, the two case examples show that to thrive, practices need to be built upon rich stories of place, understanding diversity and encouraging wide participation to ensure enough leverage and support (Mang and Reed 2017). Such participatory processes can, hence, transform stakeholders into co-creators and steady stewards of progressive solutions.

\section{Discussion: a trilateral approach to transformative place-shaping}

Returning to the main argument, the trilateral approach to transformative social innovation developed above provides a novel understanding in terms of the people-place relationships, and how interaction between regeneration, learning and experiencing as overlapping, transformative processes, can help with the reconceptualization of relationships between people and place, as elaborated in Fig. 1 above.

Learning, specifically place-based transformative learning, focuses on the vital processes of perspective transformation needed to drive sustainability transformations at different spatial scales. This means breaking away from the traditional transmissive models of education and exploring experiential pedagogies with the potential to root the learning in people-place relations and grounded in the surrounding communities. Place-based transformative learning as an approach can uncover and foster the valuable learning processes involved in sustainable and regenerative placeshaping initiatives. The theory of transformative learning represents an opportunity for a substantial basis of empirical research to contribute practically and conceptually to sustainability science. What has also been shown by the place-based approach to transformative learning is that an understanding of learning processes both complements and is strengthened by other perspectives on sustainable placeshaping. Sustainability initiatives which are grounded in place-based knowledge and regenerative practices provide rich spaces of transformative learning. Furthermore, to understand these interactions, engage different actors, and value different ways of knowing, we need new approaches to research and new research methods.

Experiencing place is an evolutionary process of sensemaking, which occurs over time by means of relational interactions between people, their settings, and their social world. It is a dynamic, complex, and multisensorial process that, if better understood, may be valuable for revealing people's place-based knowledge and place contextualization as one of the requisites for regeneration. Participatory and creative visual methods are considered an appropriate way to unveil diverse, multi-layered, and sensorial narratives of place and place practices as well as varied values and meanings attached to it. Such approaches can serve as an alternative that respects the complexity, social fabric, geography, and socio-political contexts of people and places (Lucarelli and Giovanardi 2014; Rebelo et al. 2019).

Regeneration in a place-based perspective intends to reverse the adverse human impact on the environment and create conditions for all life systems to thrive (Axinte et al. 2019). Regenerative undertakings have two main roles: to acquire a whole-systems understanding and (co-)design actions in harmony with place; and, to create platforms where stakeholders "can step up as co-creators and stewards of those actions" (Mang and Reed 2017: 18). There is, however, a need to be aware of the "risks associated with discourse and practice that constructs transformation as apolitical, inevitable, or universally beneficial" (Blythe et al. 2018: 1218) and the issues with transformation becoming an empty signifier without a coherent theoretical base. It is this, as well as a tendency in some branches of sustainability literature to readily critique concepts and seek to develop new, more radical terminology, that are cause for concern.

In proposing and considering the integrating processes of place-based learning, experiencing and regeneration practices within sustainability science, it is vital to engage with the established body of practical and theoretical knowledge as well as contributing with the disciplinary viewpoints. Sustainability scientists interested in exploring learning processes are urged to reach further than recent literatures in the field of sustainability to the origins of the theory. Transdisciplinary research is necessary if we are to have a hope of tackling the complex and multifaceted challenges of sustainability, but this is not a task to be taken lightly and we have not broken down the walls of our disciplinary silos yet.

\section{Conclusion}

By integrating our three place-shaping practices (Fig. 1) within an overall transformative social innovation framework, we are attempting to progress and posit how real sustainable and place-based transformations can occur and indeed be multiplied. This approach suggests that, given the importance of these more fine-grained social innovations, it is now timely and important to move beyond the more generic and aggregated concepts around 'sustainability', 'resilience', or adaptation/adaptive capacities which 
have previously infused many of the sustainability science debates. Deeper and more practice-based studies are needed which involve the combinations of the 'triple lenses' outlined here of transformative and place-based learning, place-based experiences, and regenerative actions and initiatives at multiple scales and sites. This allows for more spatially socio-cultural nuanced and deeper investigations of what really brings about social innovation for sustainable place-shaping.

Neither should we be reticent in explicitly focussing on how places themselves-as assemblages of social-ecological-cultural and physical assets-contribute to, and then affect and influence social relations and actions. Learning, experiencing, and regenerating emerge out of the physical and social understandings and reactions to places in which people live, work, and visit: that is their socio-material existences and practices. New socially innovative agency is created by the dynamic interaction of these processes which are driven by normative goals and intentionalities leading to place-based community empowerment and transformation. We have been capturing this agency in the series of SUSPLACE research projects referred to above and also in this Special Feature. These intentionalities are associated in various ways with relearning, reexperiencing, and, indeed, regenerating those places in more sustainable ways. We argue, therefore, that a trilateral approach linking the active and grounded processes of learning, experiencing, and regenerating becomes significant dimensions of social innovation which emerge out of places themselves, and which can then, in turn, potentially and more sustainably reshape those places in a transformative way. This approach, one which links and co-produces sustainability science research with the in-situ actors and agencies in and through places, begins to uncover some of the key dimensions of what can realistically unpack and be regarded as transformative processes.

The analysis and frameworks developed here also caution against not only a reliance of all-encompassing conceptualisations of a generic nature, and in depoliticising the idea of sustainable transformations, they also warn against premature and top-down prescriptions which attempt to 'solve' place-based sustainability problems. Rather, a major message from this body of research contains a strong element of place-based community empowerment which enables and reenforces sustainable transformations through relearning, reexperiencing and regenerating from below; but doing so by combining holistic and systems thinking with an appreciation of the inherent rooted diversity of place.

The paper has also begun to elaborate on the three broader questions initially posed in the Introduction to the paper and empirically applied using the trilateral approach concerning, path-breaking avenues for sustainable transformations, the main change agents, and how collective place-based knowledges are developed and mobilised to create social innovations. The resulting framework developed begins to map out and encompass some of the means and tools which are needed to further examine these questions. The active and socially innovative practices of learning, experiencing, and regenerating are ways in which place-based knowledges are mobilised through the bringing together of key actors and agents, creating, as we have seen by reference to a series of related SUSPLACE projects, path-breaking avenues for potential overall sustainable transformations. This is critical work for sustainability science given the dynamic and unstable context in which it now sits, and where spatially diverse and sensitive solutions and new knowledges to unsustainable practices are urgently required.

Acknowledgements The authors are grateful to the SUSPLACE consortium members and fellows as well as the editors of this Special Feature Dirk Roep, Lumima Horlings, and Erik Mathijs for their suggestions on the earlier drafts.

Funding This project has received funding from the European Union's Horizon 2020 research and innovation programme under the Marie Skłodowska-Curie Grant agreement no. 674962.

Open Access This article is distributed under the terms of the Creative Commons Attribution 4.0 International License (http://creativeco mmons.org/licenses/by/4.0/), which permits unrestricted use, distribution, and reproduction in any medium, provided you give appropriate credit to the original author(s) and the source, provide a link to the Creative Commons license, and indicate if changes were made.

\section{References}

Abson DJ, Fischer J, Leventon J, Newig J, Schomerus T, Vilsmaier $\mathrm{U}$, von Wehrden H, Abernethy P, Ives CD, Jager NW, Lang DJ (2017) Leverage points for sustainability transformation. Ambio 46(1):30-39

Arthur L (2013) Reflections on the form and content of Participatory Action Research and implications for social innovation research. In: Moulaert F, MacCallum D, Mehmood A, Hamdouch A (eds) The international handbook on social innovation: collective action social learning and transdisciplinary research. Edward Elgar, Northampton MA, pp 332-340

Avelino F, Wittmayer JM, Pel B, Weaver P, Dumitru A, Haxeltine A, Kemp R, Bauler T, Ruijsinkg S, O'Riordan T (2017) Transformative social innovation and (dis) empowerment. Technol Forecast Soc Chang. https://doi.org/10.1016/j.techfore.2017.05.002

Axinte LF (2017) Formalising the informal temporary use of vacant spaces. In: Stoustrup S (ed) Cities: changes, places, spaces. anthology of articles building on master theses from the 4cities master programme in urban studies 6th cohort, 2013-2015, University of Vienna, Department of Geography and Regional Research, pp 13-31.

Axinte LF, Mehmood A, Marsden T, Roep D (2019) Regenerative city-regions: a new conceptual framework. Region Stud Region Sci 6(1):117-129

Bäckman M, Pitt H, Marsden T, Mehmood A, Mathijs E (2019) Experiential approaches to sustainability education: towards learning 
landscapes. Int J Sustain High Educ 20(1):139-156. https://doi. org/10.1108/IJSHE-06-2018-0109

Baker S, Mehmood A (2015) Social innovation and the governance of sustainable places. Local Environ 20(3):321-334

Blythe J, Silver J, Evans L, Armitage LD, Bennett NJ, Moore M-L, Morrison TH, Brown K (2018) The dark side of transformation: latent risks in contemporary sustainability discourse. Antipode 50:1206-1223. https://doi.org/10.1111/anti.12405

Born B, Purcell M (2006) Avoiding the local trap: scale and food systems in planning research. J Plan Educ Res 26(2):195-207

Burns HL (2015) Transformative sustainability pedagogy: learning from ecological systems and indigenous wisdom. J Transform Educ 13(3):259-276

Butler-Kisber L, Poldma T (2010) The power of visual approaches in qualitative inquiry: the use of collage making and concept mapping in experiential research. J Res Pract 6(2):Article M18. https://jrp.icaap.org/index.php/jrp/article/view/197/196

Calleja C (2014) Jack Mezirow's conceptualisation of adult transformative learning: a review. J Adult Contin Educ 20(1):117-136

Cole RJ (2012) Regenerative design and development: current theory and practice. Build Res Inf 40(1):1-6

Cresswell T (2014) Place: an introduction. Wiley, Oxford.

Davies H (2016) The well-being of future generations (Wales) Act 2015. Environ Law Rev 18:41-56

du Plessis C (2012) Towards a regenerative paradigm for the built environment. Build Res Inf 40:7-22

Fazey I, Schäpke N, Caniglia G et al (2018) Ten essentials for actionoriented and second order energy transitions, transformations and climate change research. Energy Res Soc Sci 40:54-70

Felcis E (2019) Sustainability transformations through permaculture (June). https://www.youtube.com/watch?v=ypjsMc6Cdx4. Accessed 27 July 2019

García M, Eizaguirre S, Pradel M (2015) Social innovation and creativity in cities: a socially inclusive governance approach in two peripheral spaces of Barcelona. City Culture Soc 6(4):93-100

Girardet H (2015) Creating regenerative cities. Routledge, New York

Grenni S, Soini K, Horlings LG (2019) The inner dimension of sustainable transformation: How sense of place and values can supportsustainable place shaping. Sustain Sci. https://doi.org/10.1007/ s11625-019-00743-3

Gruenewald DA (2003) The best of both worlds: a critical pedagogy of place. Educ Res 32(4):3-12

Horcea-Milcu AI, Abson DJ, Apetrei CI, Duse IA, Freeth R, Riechers M, Lam DPM, Dorninger C, Lang DJ (2019) Values in transformational sustainability science: four perspectives for change. Sustain Sci:1-13.

Horlings LG (2015) Values in place; a value-oriented approach toward sustainable place-shaping. Region Stud Region Sci 2(1):257-274

Horlings LG (2016) Connecting people to place: sustainable placeshaping practices as transformative power. Curr Opin Environ Sustain 20:32-40. https://doi.org/10.1016/j.cosust.2016.05.003

Horlings LG (2018) Politics of connectivity: the relevance of placebased approaches to support sustainable development and the governance of nature and landscape. In: Marsden T (ed) SAGE handbook of nature. Sage, London, pp 304-324

Horlings LG, Nieto-Romero M, Pisters S, Soini K (this issue) Operationalising transformative sustainability science through placebased research: the role of researchers. Sustain Sci (under review)

Ichioka S (2018) Obituary for sustainability (1987-2018). https://www. citylab.com/perspective/2018/12/2018-ideas-david-zipper-steph en-goldsmith-sarah-deer-okereke/578605/. Accesssed 6 Jan 2019

Kitchenham A (2008) The evolution of John Mezirow's transformative learning theory. J Transform Educ 6(2):104-123

Lang DJ, Wiek A, Bergmann M, Stauffacher M, Martens P, Moll P, Swilling M, Thomas CJ (2012) Transdisciplinary research in sustainability science: practice, principles, and challenges. Sustain Sci 7(1):25-43

Lange EA (2004) Transformative and restorative learning: a vital dialectic for sustainable societies. Adult Educ Q 54(2):121-139

Leal Filho W, Raath S, Lazzarini B, Vargas VR, de Souza L, Anholon $\mathrm{R}$, Orlovic VL (2018) The role of transformation in learning and education for sustainability. J Clean Prod 199:286-295

Leicht A, Heiss J, Byun WJ (2018) Issues and trends in education for sustainable development, $\mathrm{p}$ 271. https://unesdoc.unesco.org/image s/0026/002614/261445e.pdf

Lotz-Sisitka H, Wals AE, Kronlid D, McGarry D (2015) Transformative, transgressive social learning: rethinking higher education pedagogy in times of systemic global dysfunction. Curr Opin Environ Sustain 16:73-80

Lucarelli A, Giovanardi M (2014) The political nature of brand governance: a discourse analysis approach to a regional brand building process. J Public Affairs 16(1):27-39

Lyle JT (1994) Regenerative design for sustainable development. Wiley, Hoboken

Mang P, Haggard B (2016) Regenerative development: a framework for evolving sustainability. Wiley, Hoboken

Mang P, Reed B (2017) Regenerative development and design. In: Meyers RA (ed) Encyclopedia sustainability science and technology, 2nd ed

Marsden TK (2013) Sustainable place-making for sustainability science: the contested case of agri-food and urban-rural relations. Sustain Sci 8(2):213-226

Massey D (1994) A global sense of place. Marxism Today.

McDougall D (2011) Anthropological filmmaking an empirical art. SAGE Handb Vis Res Methods 5:100-112

Mehmood A (2016a) Institutional forms of social innovation. Int J Innov Sustain Dev 10(3):300-311

Mehmood A (2016b) Of resilient places: planning for urban resilience. Eur Plan Stud 24(2):407-419

Mezirow J (1978) Perspective transformation. Adult Educ Q $28: 100-110$

Mezirow J (1996) Contemporary paradigms of learning. Adult Educ Q 46:158-172. https://doi.org/10.1177/074171369604600303

Mezirow J and Associates (2000) Learning as transformation: critical perspectives on a theory in progress. Jossey Bass, San Francisco

Moriggi A, Soini K, Roep D (2019) Exploring enabling resources for place-based social entrepreneurship: a participatory study of Green Care practices in Finland. Sustain Sci. https://doi. org/10.1007/s11625-019-00738-0

Moulaert F, Mehmood A (2011) Spaces of social innovation. In: Pike A, Rodríguez Pose A, Tomaney J (eds) Handbook of local and regional development. Routledge, London, pp 212-225

Moulaert F, MacCallum D, Mehmood A, Hamdouch A (eds) (2013) The international handbook on social innovation: collective action, social learning and transdisciplinary research. Edward Elgar, Cheltenham

Moulaert F, Mehmood A (2019) Towards a social innovation (SI) based epistemology in local development analysis: lessons from twenty years of EU research. Eur Plan Stud. https://doi. org/10.1080/09654313.2019.1639401

National Assembly for Wales (2015) Well-being of future generations (Wales) Act 2015. Cardiff

Pearson KR, Bäckman M, Grenni S, Moriggi A, Pisters S, de Vrieze A (2018) Arts-based methods for transformative engagement: a toolkit. SUSPLACE, Wageningen

Peet R (1985) The social origins of environmental determinism. Ann Assoc Am Geogr 75(3):309-333

Pelling M (2014) Transformation: a renewed window on development responsibility for risk management. J Extreme Events 1:1

Pink S (2001) Doing ethnography: images, media and representation in research. Sage, London 
Peters MA, Wals AEJ (2016) Transgressive learning in times of global systemic dysfunction: interview with Arjen Wals. Open Rev Educ Res 3:179-189. https://doi.org/10.1080/23265 507.2016.1217166

Pisters SR, Vihinen H, Figueiredo E (this issue) Inner change and sustainability initiatives-exploring the narratives from ecovillagers through thelens of place-based transformative learning. Sustain Sci (under review)

Rebelo C, Mehmood A, Marsden T (2019) Co-created visual narratives and inclusive place branding: a socially responsible approach to residents' participation and engagement. Sustain Sci. https://doi.org/10.1007/s11625-019-00760-2

Relph F (1976) Place and placelessness. Pion, London

Stott N, Tracey P (2018) Organizing and innovating in poor places. Innovation 20(1):1-17

Taylor EW (2007) An update of transformative learning theory: a critical review of the empirical research (1999-2005). Int J Lifelong Educ 26:173-191. https://doi.org/10.1080/02601370701219475

Taylor EW (2017) Transformative Learning Theory. In: Laros A, Fuhr T, Taylor EW (eds) Transformative learning meets building: an international exchange. Sense Publishers, Rotterdam, pp 17-29

Taylor EW, Cranton P (2013) A theory in progress?: issues in transformative learning theory. Eur J Res Educ Learn Adults $4(1): 35-47$
Temper L, Walter M, Rodriguez I, Kothari A, Turhan E (2018) A perspective on radical transformations to sustainability: resistances, movements and alternatives. Sustain Sci 13(3):747-764

Tuan YF (1980) Topophilia: a study of environmental perception, attitudes and values. Columbia University Press, New York

Vanclay FM (2008) Place Matters. In: Vanclay F, Higgins M, Blackshaw A (eds) Making sense of place: exploring concepts and expressions of place through different senses and lenses. National Museum of Australia Press, Canberra, pp 3-11

Wahl DC (2016) Creating sustainability? join the re-generation! Ecologist, 25 April. https://www.theecologist.org/green_green_livin g/2987587/creating_sustainability_join_the_regeneration.html. Accessed 6 Mar 2019

Wals AE (2010) Mirroring, gestaltswitching and transformative social learning: stepping stones for developing sustainability competence. Int J Sustain High Educ 11(4):380-390

Wittmayer JM, Schäpke N (2014) Action, research and participation: roles of researchers in sustainability transitions. Sustain Sci 9(4):483-496

Publisher's Note Springer Nature remains neutral with regard to jurisdictional claims in published maps and institutional affiliations. 